\title{
Aquatic physical therapy for Parkinson's disease
}

\author{
Talita Gianello Gnoato Zotz ${ }^{1^{*}}$, Eliani Arruda Souza ${ }^{2}$, Vera Lúcia Israel ${ }^{3}$, \\ Ana Paula Cunha Loureiro ${ }^{4}$ \\ ${ }^{1}$ Physical Therapy Department, Federal University of Paraná, Matinhos, Brazil; *Corresponding Author: talita.gnoato@gmail.com \\ ${ }^{2}$ Physical Therapy Clinic, Curitiba, Brazil \\ ${ }^{3}$ Physical Therapy Department, Federal University of Paraná, Curitiba, Brazil \\ ${ }^{4}$ Department of Physical Therapy, School of Health and Biosciences Pontifical Catholic, University of Paraná, Curitiba, Brazil
}

Received 11 June 2013; revised 2 August 2013; accepted 13 August 2013

Copyright (C) 2013 Talita Gianello Gnoato Zotz et al. This is an open access article distributed under the Creative Commons Attribution License, which permits unrestricted use, distribution, and reproduction in any medium, provided the original work is properly cited.

\begin{abstract}
One of the predominant effects of PD is alteration of motor skills, which leads to compromised posture and physical balance. Aquatic physical therapy, performed in a heated pool, can serve as one of intervention alternatives for PD carriers. Aim: To analyze the effects of the Halliwick Concept hydrotherapy in acquisition of motor skills in Parkinson's disease (PD) patients. Methods: A clinical, qualitative method was used to evaluate 7 volunteers $(59.85 \pm 7.92$ years of age, both male and female), who were in II and III stages of PD according to the Hoehn \& Yar Scale. The participants were evaluated in the start and end of the interventions phase, and then the evaluation was conducted interventions in a heated pool $\left(32^{\circ} \mathrm{C}-34^{\circ} \mathrm{C}\right)$ twice a week, each session lasting approximately 30 minutes, totaling 10 sessions. The Halliwick Principles' 3phase 10-point methods were used for acquisition of aquatic motor skills. Results: They indicate an improvement in their ability to float in prone and supine positions $\left(P=0.04^{*}\right)$ and longitudinal rotation in the bipedal position. Conclusion: The activation of motor control improved the motor skills of the participants.
\end{abstract}

Keywords: Parkinson's Disease; Motor Skills; Hydrotherapy; Halliwick Concept

\section{INTRODUCTION}

The process of aging in the human includes psychological, emotional, social and biological alterations, which can be quite apparent and obvious throughout the body [1]. Certain diseases can trigger and accelerate the aging process, as documented in Parkinson's disease, which is a chronic and progressive disturbance of the nervous system, more specifically the ganglions of the base and eventually resulting in abnormal posture and involuntary movements [2].

The knowledge about the possible factors in the physiopathology of PD also demands an inevitable investigation of the pertinent questions about natural aging of the human being. And these investigations can also lead to further development of a repertoire of preventive physiotherapeutic methods by the intervention team for PD patients.

With the clinical diagnosis of PD, the individual may show an alteration in postural reactions such as straightening, balance, protective extension, difficulty in corporal rotation and reduced muscular strength [3]. Such symptoms are accentuated when the patient is subjected to situations of stress, fatigue or pressure, which can exacerbate the freezing phenomenon and postural compromise, leading to a sudden loss of balance [4].

In order to slow down the progression of the disease, one can try various physical therapy intervention procedures such as exercising on a treadmill with partial support weights [5], adaptive exercise programs with multimodalities [6], resistance training [7] and stimulus for motor skill learning [8]. In addition, aquatic physical therapy (APT) is currently used as a treatment for individuals with PD in clinical practice [9]. Some authors have suggested this kind of therapy as a means to improve the quality of life, reduce postural instability and the risk of falling in the elderly, and to enhance treatments for different disorders $[9,10]$.

The approach of APT can be defined as a practice of methodologies and concepts in a heated pool [9] whose objective is the kinetic recovery of a physically debilitated individual $[11,12]$. Being able to participate clinically in a pool is one of the requirements for aquatic therapy interventions. The liquid medium with the proper 
hygiene and temperature enables the physiologic and therapeutic benefits for neurological patients such as in the case of PD.

In addition, APT uses the physical properties such as resistance noted in Archimedes' and Pascal's Principle [11]. These aquatic effects are versatile and can be advantageous for the use of therapeutic intervention of PD patients. Buoyancy and hydrostatic pressure offered by water provide extra support for the participant to perform the proposed exercises and reduce the velocity of falls [9].

The Halliwick Concept, created by James McMillan in England, is based on scientific principles of hydrodynamics and body mechanics [13] and encourages the independence of the person in water. The method [8] developed with recreational activities in three-stage and ten-point teaches aquatic motor skills in a subtle way.

The application of APT depends on two assessments: wet and dry. The wet evaluation [15] should assess the following skills: entry into and exit out of the pool, respiratory control and control of basic movements inside the water.

This study was conducted with the objective of analyzing the efficacy of the Halliwick aquatic therapy in the acquisition of motor skills of PD patients.

\section{METHODS}

This research's clinical and qualitative evaluation intentions [16] were approved by the ethics committee of the Pontifical Catholic University of Parana (PUCPR No 1995/07). The study sample consisted of seven subjects (mean age $59.85 \pm 7.92$ years of male and female) in Stage II and III on the Hoehn and Yahr Scale of PD [17] (time since diagnosis $7.85 \pm 3.80$ years).

The following criteria were considered to inclusion: clinically diagnosed as Parkinson's disease, ages between 40 and 70 years and participants personally read and signed the Terms of Agreement. And to exclusion: inability to walk, blindness, clinically diagnosed dementia, severe interference with oral communication, fear of water or any signs and symptoms that may put their health at risk while performing aquatic therapeutic exercises.

\section{Procedures}

a) Collection of Data

In the data collection, an initial interview was carried out to collect volunteers' age, sex, duration of illness, use of assistive devices and medications. Subsequently, an aquatic evaluation [13] was made at the start and end to the intervention phase. Participants received a score based on performance in executing the aquatic motor skills of various levels of difficulty [11] (Table 1). Their blood pressure was monitored at the start and end of each intervention with the purpose of observing the evolution
Table 1. Aquatic Motor Skills.

\begin{tabular}{cc}
\hline Grades & Description of skills \\
\hline 5 & $\begin{array}{r}\text { Performs movement without help, with } \\
\text { complete motor control }\end{array}$ \\
4 & Performs movement without help, with motor control \\
3 & Performs movement without help, with partial motor \\
2 & control Performs movement with 1 or 2 supports \\
1 & Performs movement with 1 or 2 supports \\
\hline
\end{tabular}

of the vascular response to exercise.

b) Hydrotherapeutic Intervention

The intervention was preceded by an introductory demonstration and orientation of the exercises with each patient. Ten therapeutic interventions in total, twice a week, were performed in a heated swimming pool (average temperature between $32^{\circ} \mathrm{C}$ and $34^{\circ} \mathrm{C}$ ). They were conducted lasting 30 minutes each and covered the three phases and 10 points of the Halliwick Concept.

The exercises were developed and implemented with objectivity to minimize any biases and partiality between the two groups of patients.

b.1) Aquatic Intervention Program

The exercises were aimed at the functional motor skill potential in an aquatic assessment. The intervention program also sought repeatibility [14] of the procedures in any follow-up studies and is described below [18].

Type: Front Entry from the pool edge with support in the Armpits.

Phase I-Mental Adaptation

Step 1-Mental Adjustment

Phase II-Control of Balance

Stept 2-Control of Sagittal Rotation

Step 3-Control of Transversal Rotation

Step 4-Control of Longitudinal Rotation

Step 5-Control of Combined Rotation

Step 6-Buoyancy

Step 7-Balance in Stillness

Step 8-Turbulent Gliding

Step 9-Simple Progression

Phase III-Control of Movements

Step 10-Basic Movements of the Halliwick

Exiting the Pool: The exit entails the participant walking up the stairs or ladder to get out of the pool.

c) Statistic Analysis

The sample was characterized as non-parametric due to the heterogeneity of the group (time since onset of illness, age, weight, sex, medication, blood pressure). The software Statistic 7.0 was used to perform a Wilcoxon test on the data, with a reference value $\mathrm{p} \leq 0.05$.

\section{RESULTS}

The obtained results show that after the aquatic inter- 
vention the PD participants improved significantly some motor abilities, the end was compared to he same. Among the analyzed functional aquatic motor skills related to balance, we highlight the buoyancy in the prone position $\left(\mathrm{P}=0.04^{*}\right)$ and supine $\left(\mathrm{P}=0.04^{*}\right)$ (Figure 1) to rotations: sagittal $(\mathrm{P}=0.133)$, combined $(\mathrm{P}=0.073)$, longitudinal to the right $\left(\mathrm{P}=0.041^{*}\right)$, longitudinal to the left $\left(\mathrm{P}=0.041^{*}\right)$, transversal-supine/prone $(\mathrm{P}=0.248)$ and transversal-prone/supine $(\mathrm{P}=0.248)$; striding: forward $(P=0.108)$, backward $(P=0.108)$, hops $(P=0.067)$ and lateral $\left(\mathrm{P}=0.043^{*}\right)$ (Figure 2).

\section{DISCUSSION}

Aquatic Physical Therapy can be used with therapeutic efficacy for a great variety of rehabilitative problems. Aquatic exercise has been successfully used to improve balance and coordination special in older individuals [10,19-21]. It may be an excellent alternative to land exercise for individuals who lack confidence, have a high risk of falling, or have joint pain that limits their ability to practice center-of-gravity shifts beyond the limits of their base of support [22]. Even though aquatic exercise has been shown to be an effective strategy for reducing postural instability, to our knowledge, very few interventions have been performed in this environment with patients suffering from PD.

Significant improvements in balance in this study suggest that the Halliwick Concept can be a viable alternative for people with PD. The phases described by Israel [11] in Aquatic Physical Therapy advocate that greater utilization of aquatic motor skills in neurological patients is fundamental in the two phases because the patient becomes familiar with the pool and adjusts his clinical condition and motor skill potential of this learning process.

The training of aquatic motor skills through the Halliwick activities $[4,11]$ allowed the body control through flotation and rotation The control of metacenter and any occuring changes stimulates balance in the water and motor-sensory adjustments. This is because the execu-

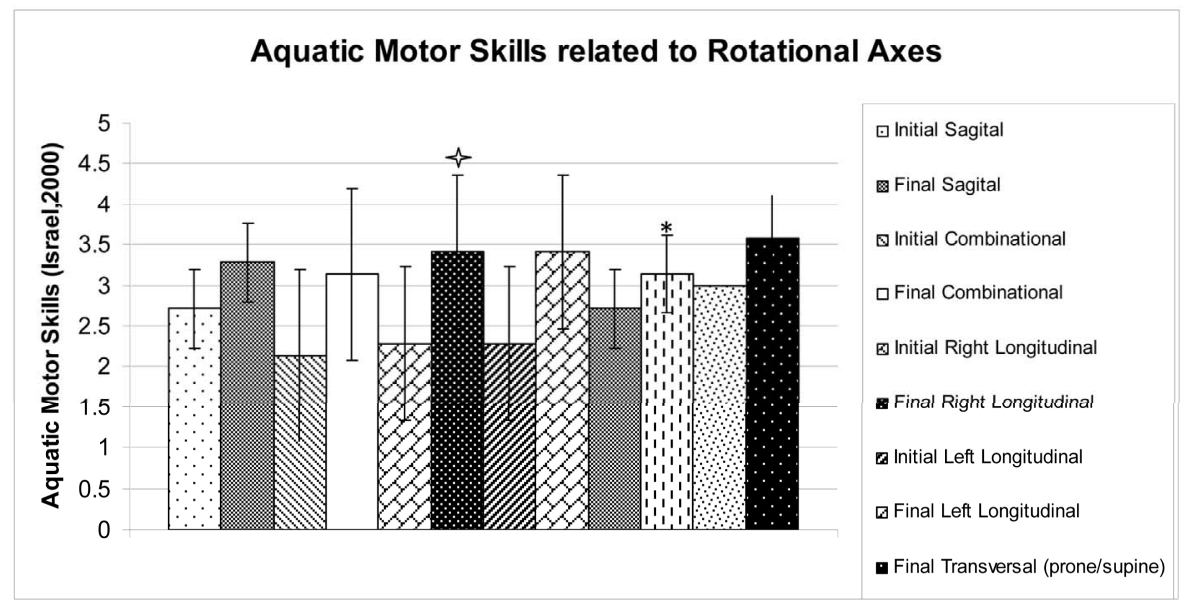

Figure 1. Aquatic motor skills related to floatability. $\& p \leq 0.05$ when comparing Floatability with Initial Prone after intervention (Wilcoxon); ${ }^{*} \mathrm{p} \leq 0.05$ when comparing Floatability with Initial Supine after intervention (Wilcoxon).

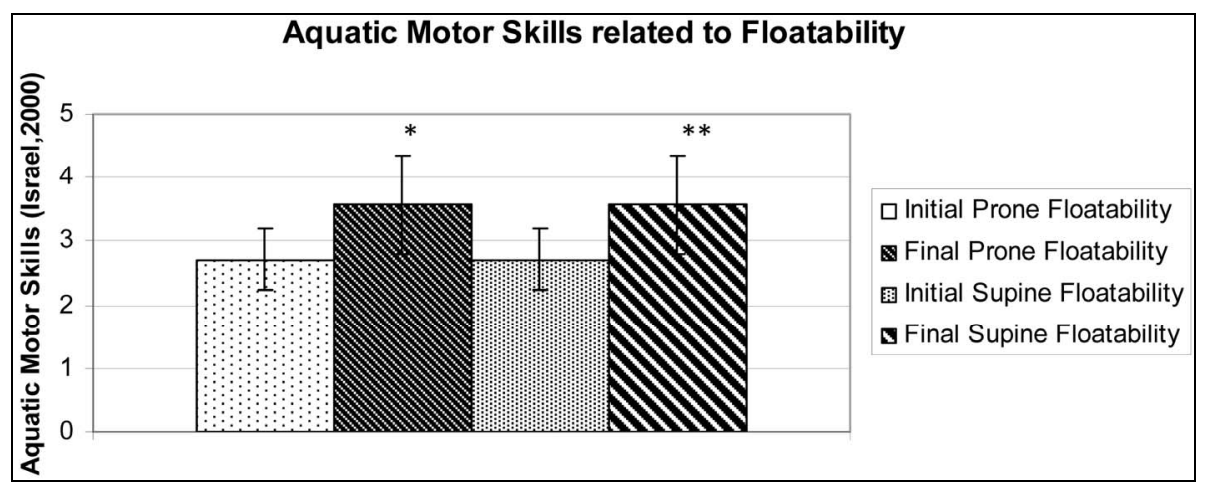

Figure 2. Aquatic motor skills related to rotational axes. $\diamond p \leq 0.05$ when comparing Longtitudinal Rotation with Initial Right after intervention (Wilcoxon); ${ }^{*} \mathrm{p} \leq 0.05$ when comparing Longtitudinal Rotation with Initial Left after intervention (Wilcoxon). 
tion of water skills provides proprioceptive motor strategies in a three-dimensional way through movements of the head, neck, eyes and vestibular system. The success of the patients in floatability may have happened due to the higher positioning of the body in the pool which led to better control of the body in the liquid medium.

The statistical significance in control of right and left longitudinal rotation is a motor skill that allowed a dissociation of the shoulders from the pelvic. This decoupling is useful in many daily functional skills such as walking, reaching for objects, and standing up, among others. The PD patient shows a reduction of these skills with the advancement of the disease, so these achievements were of great value to these participants. Such gains, probably helped the volunteers to work some principles of motor control and, thus, favored the body posture by the constant adaptation of muscle activity throughout the body during immersion [1].

Other relevant factors to be considered for activating postural control of the participants are the following: a constant voluntary muscle contraction as a result of sensitization of the vestibular system due to fluctuations in the water body during the execution of movement patterns; activation of the somatosensory system that recognizes these different positions of body segments during ranges of motion and leading to an enhancement of the systems settings equilibrium [23].

The positive development of motor skills of the participants can be also attributed to the stimulation neurological reactions by the water continuous loss and recovery of balance by turbulent flows [15]. In search of stable equilibrium, the receptors are engage in postural adjustments [24].

In the case of the corporal buoyancy, one of the exercises in this research, the Archimedes Principle helps the participant to maintain control of the body in the pool resulting in flotation [3] in the prone and supine position. An excessive muscle contraction or a loss of balance can lead to muscle tension or stiffness in the body segments and result in a change of the relative density of the body. This changes the metacenter and promotes corporal rotation $[15,25]$. Exercises in varied conditions and environments help the patient relearn the principles of postural checks and balances 23 or at least postpone the adverse clinical conditions in PD.

Aquatic exercise and rehabilitation remains vastly underused despite its recent increase in popularity. This study produced results which corroborate the findings of great deal of the research in this field. A 2013 study assessing a own protocol of 16 sessions aquatic exercise in a group of 13 patients with $\mathrm{PD}$, in stages from mild to moderate, has evaluated the quality of life using the Parkinson's Disease Questionnaire 39 (PDQ-39) .The presented results have shown a statistically significant reduction in the total score of the PDQ-39 and in all areas including mobility [26].

Vivas, Arias e Cudeiro [9] carried out a study to compare the effects of an aquatic therapy versus conventional land-based exercise program with 11 individuals with PD for 4 weeks. Aquatic therapy in the applied protocol has seemed to be more effective than land-based protocols in some assessments like Berg Balance Scale (BBS) and the Unified Parkinson's Disease Rating Scale (UPDRS).

A 2012 study assessed different forms of aquatic exercise with activities aimed at gaining balance, strength and coordination in a group of 13 PD subjects, lasted for 12 weeks, finding an improvement, especially in the sample's fitness level and in their ability to perform activities of daily living [27].

Ayán and Cancela [28] also determined the effects of aquatic therapy in an exploratory pilot study. The 20 PD participants were divided in 2 groups. They have analyzed the effects of 2 different water-based exercise physical training programs, a low-intensity water exercise program and a muscular resistance water exercise intervention. The results obtained reveal that both interventions can have beneficial effects in the quality of life. However, it seems that the performance of a water-based exercise muscular resistance program leads to greater and significant changes in functional mobility and motor symptoms.

Hartley and colleagues [29] realized a case study with one female sedentary patient with diagnose of osteoarthritis, Parkinson's disease and depression to investigate the effects of 12 aquatic physical therapy interventions over 5 weeks. The aquatic exercises promoted an improvement in range of motion, strength, balance, gait, depression and quality of life.

In the study by Andrade et al. [26] with seven individuals with $\mathrm{PD}$, the water exercise intervention was conducted for 4 weeks. The Berg Balance Scale (BBS) and Timed up and Go test (TUGT) were used to assess functional balance impairment. It was observed a significant increase in the BBS scores and a reduction of the TUGT.

An earlier study assessing aquatic and land exercises in 16 patients with PD was designed as an open long-term pilot trial over 20 weeks. Once per week the training was performed in warm water to increase muscle strength against the water resistance and to reduce trunk stiffness and rigidity. The second training program of the week was held in land to improve initiation of movements, gait, flexibility, and coordination of motor skills. Motor disability as well as mood and subjective well-being improved significantly by exercise training [30].

Despite their small sample sizes, short-term studies, methodological differences, lack of a control group these studies seem to agree that aquatic exercises can improve 
health benefits related to balance and functional mobility, adding value clinical and applicability specific in the rehabilitation for this population.

\section{CONCLUSIONS}

This study taught and evaluated motor skills of PD patients in horizontal flotation and rotation (transversal, longitudinal and sagittal) in a heated pool. It appeared that the activation of motor control improved the motor skills of the participants and the Halliwick Concept enhanced the interaction between the participants and resulted in better realization of their potential and the prevention of depression that frequently manifested in PD patients [24].

Therefore, it is believed that the intervention strategy of study can be defined as another tool for health promotion, secondary prevention and treatment of Parkinson's disease [25]. In conclusion, a Halliwick aquatic therapy is of great value to the group of volunteers in this study. However, the sample size of the study is small, thus further follow-up studies, especially longitudinal studies, are suggested for evidence of scientific hydrotherapy intervention with this population.

\section{ACKNOWLEDGEMENTS}

The authors would like to thank you the people with Parkinson's disease for their cooperation.

\section{REFERENCES}

[1] Alfieri, F.M., Teodori, R.M. and Guirro, R.R.J. (2006) Estudo baropodométrico em idosos submetidos à intervenção fisioterapêutica. Fisioterapia em Movimento, 19, 67-74.

[2] O'Sullivan, S.B. (2004) Fisioterapia: Avaliação e Tratamento. 2nd Edition, Editora Manole Ltda, Rio de Janeiro.

[3] Bloem, B.R., Van Vugt, J.P. and Beckley, D.J. (2001) Postural instability and falls in Parkinson's disease. Advances in Neurology, 87, 209-223.

[4] Navarro, F.M. and Aragão, F.A. (2005) Influências do envelhecimento, do tempo de evolução da doença e do estado cognitivo sobre episódios de quedas, em uma população parkinsoniana. Revista Brasileira de Fisioterapia, 6, 250-254.

[5] Miyai, I., Fujimoto, Y., Ueda, Y., Yamamoto, H., Nozaki, S., Saito, T. and Kang, J. (2000) Treadmill training with body weight support: Its effect on Parkinson's disease. Archives of Physical Medicine and Rehabilitation, 81, 849-852. http://dx.doi.org/10.1053/apmr.2000.4439

[6] Gobbi, L.T., Oliveira-Ferreira, M. D., Caetano, M.J., Lirani-Silva, E.; Barbieri, F.A., Stella, F. and Gobbi, S. (2009) Exercise programs improve mobility and balance in people with Parkinson's disease. Parkinsonism \& Related Disorders, 15, S49-S52.

http://dx.doi.org/10.1016/S1353-8020(09)70780-1
[7] Scandalis, T.A., Bosak, A.; Berliner, J.C.; Helman, L.L. and Wells, M.R. (2001) Resistence training and gait function in patients with Parkinson's disease. American Journal of Physical Medicine \& Rehabilitation, 80, 38-43. http://dx.doi.org/10.1097/00002060-200101000-00011

[8] Jessop, R.T., Horowicz, C. and Dibble, L.E. (2006) Motor learning and Parkinson disease: Refinement of movement velocity and endpoint excursion in a limit of stability balance task. Neurorehabilitation and Neural Repair, 20, 459-467. http://dx.doi.org/10.1177/1545968306287107

[9] Vivas, J., Arias, P. and Cudeiro, J. (2011) Aquatic therapy versus Conventional Land-Based Therapy for Parkinson's Disease: An open-label pilot study. Archives of Physical Medicine and Rehabilitation, 92, 1202-1210. http://dx.doi.org/10.1016/j.apmr.2011.03.017

[10] Katsura, Y., Yoshikawa, T., Ueda, S.Y., et al. (2010) Effects of aquatic exercise training using water-resistance equipment in elderly. European Journal of Applied Physiology, 108, 957-964. http://dx.doi.org/10.1007/s00421-009-1306-0

[11] Israel, V.L. and Pardo, M.B.L. (2000) Hidroterapia: Proposta de um programa de ensino no trabalho com o lesado medular em piscina aquecida. Fisioterapia em Movimento, 13, 111-127.

[12] Gnoato, T.G., Viana, J., Sabino, J., Cruz, L., Loureiro, A.P.C. and Cidade, L. (2009) Aquatic physical therapy approach, using the Halliwick Concept, for improvement of aquatic motor skills, among Parkinson's disease patients. 18th WFN World Congress on Parkinson's Disease, Miami Beach, 2009

[13] Ruoti, R.G., Morris, D.M. and Cole, A.J. (2000) Reabilitação aquática. Manole, São Paulo.

[14] Barbosa, A.D., Camargo, de C.R., Arruda, E. de S. and Israel, V.L. (2006) Avaliação fisioterapêutica aquática. Fisioterapia em Movimento, 19, 135-147.

[15] Resende, S.M., Rassi, C.M. and Viana, F.P. (2008) Efeitos da hidroterapia na recuperação do equilíbrio e prevenção de quedas em idosas. Revista Brasileira Fisioterapia, 12, 53-57.

[16] Turato, E.R. (2003) Tratado de metodologia da pesquisa clínico-qualitativa: Construção teórico-epistemológica, discussão comparada e aplicação nas áreas da saúde e humanas. Vozes, Rio de Janeiro.

[17] Hoehn, M.M. and Yahr, M.D. (1967) Parkinsonism: Onset, progression and mortality. Neurology, 17, 573-581. http://dx.doi.org/10.1212/WNL.17.5.427

[18] Lambeck, J. and Stanat, F.C. (2001) The Halliwick method. Part 1 and Part 2. AKMA, 15, 39-41.

[19] Avelar, N.C., Bastone, A.C., Alcântara, M.A. and Gomes, W.F. (2010) Effectiveness of aquatic and non-aquatic lower limb muscle endurance training in the static and dynamic balance of elderly people. Revista Brasileira Fisioterapia, 14, 229-236.

[20] Arnold, C.M. and Faulkner, R.A. (2010) The effect of aquatic exercise and education on lowering fall risk in older adults with hip osteoarthritis. Journal of Aging and Physical Activity, 18, 245-260.

[21] Arnold, C.M., Busch, A.J., Schachter, C.L., Harrison, E.L. 
and Olszynski, W.P. (2008) A randomized clinical trial of aquatic versus land exercise to improve balance, function, and quality of life in older women with osteoporosis. Physiotherapy Canada, 60, 296-306. http://dx.doi.org/10.3138/physio.60.4.296

[22] Roth, A.E., Miller, M.G., Ricard, M., Ritenour, D. and Chapman, B.L. (2006) Comparisons of static and dynamic balance following training in aquatic and land environments. Journal of Sport Rehabilitation, 15, 299-311.

[23] Gago, I.F. and Seco, J.C. (2008) Programa de fisioterapia mejora a largo plazo las habilidades motoras en pacientes con enfermidad de Parkinson. Revista Iberoamericana de Fisioterapia y Kinesiologia, 11, 81-92. http://dx.doi.org/10.1016/S1138-6045(08)76326-3

[24] Mello, M.P.B. and Botelho, A.C.G. (2010) Correlação das escalas de avaliação utilizadas na Doença de Parkinson com aplicabilidade na fisioterapia. Fisioterapia em Movimento, 23, 121-127. http://dx.doi.org/10.1590/S0103-51502010000100012

[25] Association of Swinning Therapy (2000) Natação para deficientes. 2nd Edition, Manole, São Paulo.

[26] Andrade, C.H.S., Silva, B.F. and Corso, S.D. (2010) Efeitos da hidroterapia no equilíbrio de indivíduos com doença de Parkinson. Conscientiae Saúde, 9, 317-323. http://dx.doi.org/10.5585/conssaude.v9i2.2108

[27] Ayán, C. and Cancela, J.M. (2012) Feasibility of 2 different water-based exercise training programs in patients with Parkinson's disease: A pilot study. Archives of Physical Medicine and Rehabilitation, 93, 1709-1714

[28] Ayán, C. and Cancela, J.M. (2012) Effects of aquatic exercise on persons with Parkinson's disease: A preliminary study. Science \& Sports, 27, 300-304. http://dx.doi.org/10.1016/j.scispo.2011.12.006

[29] Hartley, G.W., Schwiering, L., Shapiro, S. and Longfellow G. (2010) The effects of aquatic physical therapy on functional mobility in a sedentary patient with osteoarthritis, Parkinson disease, and depression. Journal of Aquatic Physical Therapy, 18, 2-9.

[30] Reuter, I., Engelhardt, M., Stecker, K. and Baas, H. (1999) Therapeutic value of exercise training in Parkinson's disease. Medicine \& Science in Sports \& Exercise, 31, 1544 1549.

http://dx.doi.org/10.1097/00005768-199911000-00008 